\title{
複数の車載レーザレンジセンサによる移動物体追跡
}

\section{Moving Target Tracking with In-vehicle Multi-Laser Range Sensors}

\author{
$\bigcirc$ 橋本 雅文 (同志社大学) \\ 西村博吏（同志社大学大学院） \\ 松井洋介 (同志社大学大学院) \\ 高橋 和彦（同志社大学）

\begin{abstract}
Masafumi HASHIMOTO, Doshisha University
Yosuke MATSUI, Graduate School,Doshisha University

Hiroshi NISHIMURA, Graduate School,Doshisha University
\end{abstract} \\ Kazuhiko TAKAHASHI, Doshisha University
}

\begin{abstract}
This paper presents a method for detecting and tracking multiple moving objects with multiple 2D laser range sensors(LRS's). The coordinate systems of multiple LRS's are calibrated based on Kalman filter and Nearest Neighboring Standard Filter(NNSF). The moving objects are tracked based on Kalman filter, Covariance Intersection(CI) and the assignment algorithm. A rule based track management system is embedded into the tracking system in order to improve the tracking performance. The experimental result in indoor environments validates the proposed method.
\end{abstract}

Key word: Mobile robot, Multi-laser range sensors, Multi-target tracking, Kalman filter, Covariance intersection

\section{1.はじめに}

移動ロボット自らが班团環境をセンサにより観測し、移動 物体を認識してそ扎を追跡（位置や速度を推定）するセンシ ングシステムは、ロボットの衝突回避や協調行動などを尖現 する上で代可欠な機能である。筆者らは煩篗な環境卜にお いても車載レーザレンジセンサ(LRS)により袯数の移動物体 を検出・追跡する方法を提案してきた[1].

LRSの視野は限られていることから，ロボットの全㓮四に 対して移動物体を榆出・追跡するには複数のLRSを車載する 必要がある。本研究は，車載した複数のLRSにより襍数の移 動物体を精度よく，また，効率的に検出・追跡するシステム を構築することを目的としている。

複数のLRSでは，それぞれのLRSに設けたローカル座標系 (LRS座標系) で観測值が得られることから，裬数LRSの観 測值を統合するには基準となる基準座慓系を定め。各LRS座 標系での観測值を基準座僄系に変換する必要がある。これ には基準座標系と各LRS座慓系との相対位置・方位関係を知 ること（座標系のキャリブレーション）が必要となる。

また、ロボットには多くのセンサが搭載されることから。 センサ台数の增減に対しても対応が容易なモジュール性や 挺张性の高いセンシングシステムの構築が望まれる。この ことから，複数LRSによる移動物体検出・追跡システムにお

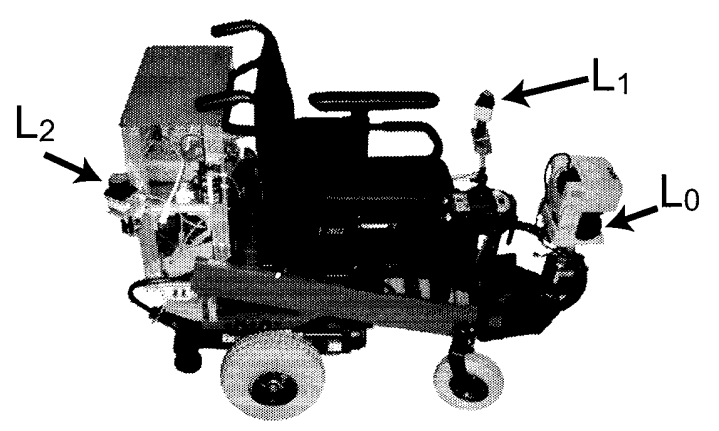

Fig.1 Overview of experimental wheelchair
いても，各LRSにより算出した移動物体検出・追跡情報を分 散的に統合して，精度よく移動物体の検出・追跡を行うこと が重要となる。

本論文では，複数のLRSに関して，そのキャリブレーショ ン法と移動物体検出・追跡法を提案する[2]。本論文の構成を 以下に示す，2.では実験システムの構成を述べる，3.では座 慓系のキャリブレーション法を、4.では移動物体追跡法を述 ベる．5.では类験と提案手法の有効性を示し，6.では結論を 述べる

\section{2. 実験システムの構成}

図1にロボット(電動車椅子)の外観を示す。ロボットには， 内界センサとして駆動輪には速度計測用レゾルバと車体旋 回速度計測用のジャイロを設けている。また。外界セン サとして，2 次元LRSを車体前部と後部に計 3 台 (SICK 社の LMS200を 1 台と北陽電機社のURG-X002Sを 2 台)取り付けて いる. 各LRSの仕様を表1に示す. LRS は方位分解能ごとに 反時計方向にパルスレーザ光を発射し，Time-of-fligt法に より対象物までの距離を計測する。以後、沧1に示すよう に，LMS200を $L_{0}$, 車体前部のURG-X002S $L_{1}$, 車体後部の URG-X002Sを $L_{2}$ と示す.

\section{3. 座標系のキャリブレーション}

\section{1 概要}

3 台のLRSの座標系は四 2 に示す関係になっている。ただ し，各LRSの座慓系は，LRSのレーザ光の発射位罱を原点 とし、レーザ光の発射方位角が $0[\mathrm{deg}]$ の方向を $X$ 軸方向と

Table1 Specification of LRS

\begin{tabular}{|l|r|r|}
\hline Product & LMS200 & URG-X002S \\
\hline Measument range[m] & 8.1 & 4.0 \\
\hline Scanning angle[deg] & 180 & 240 \\
\hline Angular resolution[deg] & 0.5 & 0.35 \\
\hline Scanning flequency[Hz] & 75 & 10 \\
\hline
\end{tabular}




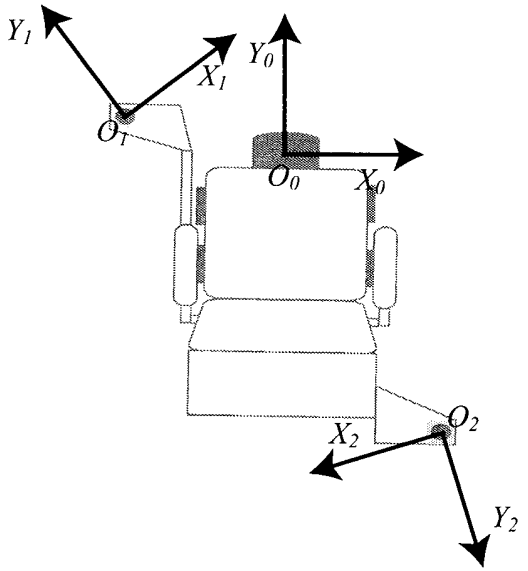

Fig.2 Coordinate system of LRS

している，以後， $L_{0}$ の座標系を $\Sigma_{0}\left(O_{0} ; X_{0} Y_{0}\right), L_{1}$ の座標系を $\Sigma_{1}\left(O_{1} ; X_{1} Y_{1}\right), L_{2}$ の座標系を $\Sigma_{2}\left(O_{2} ; X_{2} Y_{2}\right)$ とする。

$\Sigma_{0}$ を基準座標系とし， $\Sigma_{0}$ と $\Sigma_{1} ， \Sigma_{0}$ と $\Sigma_{2}$ の相対位置・方位を 求めることで， $L_{1} ， L_{2}$ の観測值を $\Sigma_{0}$ に悠換する。なお， $\Sigma_{2}$ の キャリブレーション法は同様のため, 以後， $\Sigma_{1}$ のキャリブ レーション法のみ述べる.

\section{2 カルマンフィルタ $(\mathbf{K F})$ によるキャリブレーション}

$\Sigma_{1}$ のキャリブレーションを行うためには， $L_{0}$ と $L_{1}$ で観測 した同一の特徵量を対応付ける必要がある。床に対して重 直な平面を設置し，LRSでこれらの平面を観測すると，LRS の走榃平面と泜国環境の平面との父線は直線となる。そこ で，斗3に示すように㓮团環境に2枚の平面を設罱し，その平 面を $L_{0}$ と $L_{1}$ により観測することで 4 本の直線を抽出する [3]. そして，こ机らの直線がいずれの平面に属するものか対応付

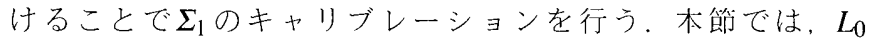
と $L_{1}$ で抽出された直線の対応付けができているものとして, $\Sigma_{1}$ のキャリブレーション法を述べ, 直線の対応付けについ ては次節で述べる。

$d_{1}=\left(d_{x_{1}}, d_{y_{1}}, d_{\phi_{1}}\right)^{T}$ を $\Sigma_{0}$ における $\Sigma_{1}$ の相対位罱・方位とする. $d_{1}$ は一定值のため, 式(1)に示す状態方程式が得られる.

$$
d_{1}(t)=d_{1}(t-1)+\Delta d_{1(t-1)}
$$

ただし， $t, t-1$ はRSの第 $t$ スキャン月，第 $t-1$ スキャン月 を示し, $\Delta d_{1(t-1)}$ は平均值 0 , 共分散 $Q_{d}(t-1)$ の正規性白色雑音 であるとする。

为 3 をもとに観測方程式を考えると式 (2) となる. $\rho_{i}^{j}(t-1)=$ $\left(r_{i}^{j}(t-1), \theta_{i}^{j}(t-1)\right)^{T}$ は $L_{i}$ が平面 $j\left(B_{j}\right)$ を観測することで得られる直 線に対する法線距離・角度である.ただし， $i=0,1, j=1,2$ で ある。

$$
\begin{gathered}
\left\{\begin{array}{c}
\rho_{1}^{1}(t)=h_{c 0}^{1}(t)+\Delta \rho_{1}^{1}(t) \\
\rho_{1}^{2}(t)=h_{c 0}^{2}(t)+\Delta \rho_{1}^{2}(t)
\end{array}\right. \\
h_{c 0}^{j}(t)=\left(\begin{array}{c}
r_{0}^{j}(t-1)-d_{x_{1}}(t) \cos \theta_{0}^{j}(t-1)-d_{y_{1}}(t) \sin \theta_{0}^{j}(t-1) \\
\theta_{0}^{j}(t-1)-d_{\phi_{1}}(t)
\end{array}\right)
\end{gathered}
$$

ただし， $\Delta \rho_{1}^{1}(t), \Delta \rho_{1}^{2}(t)$ は対応付けされた直線の法線距離・角 度の誤差であり, 平均値 0 , 共分散 $R_{c}(t)$ の正規吽白色雑音と する。

式(1)(2)をもとにKFを構成し， $\hat{d}_{1}(t)$ を推定する。そして。こ れをもとに, 次式により $L_{1}$ で得た観測值を $\Sigma_{0}$ へ座標変換する。

$$
\left(\begin{array}{c}
z_{x_{1}}^{0}(t) \\
z_{y_{1}}^{0}(t)
\end{array}\right)=\left(\begin{array}{cc}
\cos \hat{d}_{\phi_{1}}(t) & -\sin \hat{d}_{\phi_{1}}(t) \\
\sin \hat{d}_{\phi_{1}}(t) & \cos \hat{d}_{\phi_{1}}(t)
\end{array}\right)\left(\begin{array}{c}
z_{x_{1}}^{1}(t) \\
z_{y_{1}}^{1}(t)
\end{array}\right)+\left(\begin{array}{c}
\hat{d}_{x_{1}}(t) \\
\hat{d}_{y_{1}}(t)
\end{array}\right)
$$

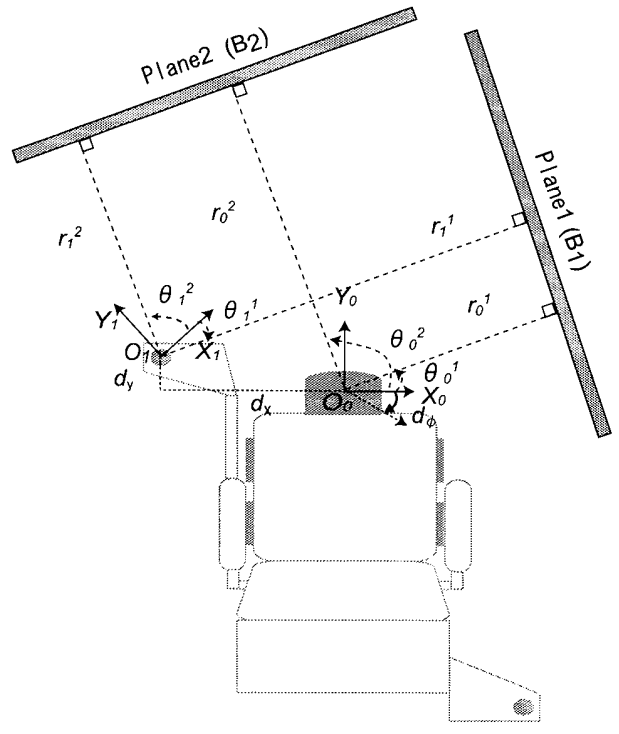

Fig.3 Notation related to calibration of coordinate system

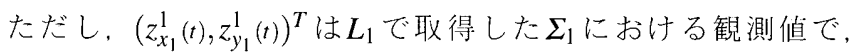
$\left(z_{x_{1}}^{0}(t), z_{y_{1}}^{0}(t)\right)^{T}$ はそれらを $\Sigma_{0}$ に少換後の観測值である。

\section{3 直線部の対応付け}

座標系のキャリブレーションをするために， $L_{0}$ と $L_{1}$ で観測 した各直線をNNSF(Nearest Neighboring Standard Filter)[4]を用 いて対応付ける。

$\rho_{0}^{j}(t)$ の観測予測值 $\hat{\rho}_{0}^{j}(t / t-1)$ を次式により予測する.

$$
\hat{\rho}_{0}^{j}(t / t-1)=\left(\begin{array}{c}
r_{0}^{j}(t-1)-\hat{d}_{x_{1}}(t) \cos \left(\theta_{0}^{j}(t-1)\right)-\hat{d}_{y_{1}}(t) \sin \left(\theta_{0}^{j}(t-1)\right) \\
\theta_{0}^{j}(t-1)-\hat{d}_{\phi_{1}}(t)
\end{array}\right)
$$

$\hat{\rho}_{0}^{j}{ }^{(t / t-1)}$ と $L_{1}$ が平面 $B_{k}$ を镍測することで得られる $\rho_{1}^{k}(t) よ り$, 観測予測䛊差 $\tilde{\rho}(t / t-1)$ と $\chi^{2}$ 值が式 (5)(6)より得られる.

$$
\begin{aligned}
& \tilde{\rho}(t / t-1)=\rho_{1}^{k}(t)-\hat{\rho}_{0}^{j}(t / t-1) \\
& \left.\chi^{2}=\tilde{\rho}(t / t-1)\right)^{T} S_{C}(t)^{-1} \tilde{\rho}(t / t-1)
\end{aligned}
$$

ただし $, j=k=1,2, S_{c}(t)=H_{c_{0}}^{j}(t) P_{d(t / t-1)} H_{c_{0}(t)}{ }^{T}+R_{c(t)}$ であ る。また， $P_{d}(t / t-1)$ は KFで用いる予測䛊差其分散， $R_{c}(t)$ は対 応付けされた直線の法線距離・角度の誤差に関する共分散， $H_{c_{0}(t)}^{j}$ は $h_{c 0}^{j}(t)$ のコビ行列である.

そこで， $\chi^{2}<a$ (閾值)を満たし，かつ $\chi^{2}$ 值を最小とする直 線同士を対応付ける。これにより， $\rho_{1}^{1}(t)$ と $\rho_{0}^{1}(t-1), \rho_{1}^{2}(t)$ と $\rho_{0}^{2}(t-1)$ を対応付けることができる。

\section{4. 移動物体追跡法}

複数LRSによる少行者追跡に関して，文献[5]では各LRSか らの情報をネットワークを介して1台のコンピュータに集 め，集中処理を行うセンシングシステムを提案している。本 研究では，七ンサ台数の增減に対しても対応が容易なモ ジュール性や抎張性の高いセンシングシステムで移動物体 追跡を行うことを月指している。そのため，汹4に亦すよう に，各LRSにコンピュータを1台制り当て，コンピュータ間 をネットワークで接続するセンシングシステムを構成する。 本章では，各LRS単独での移動物体追跡法を述べ，次に，複 数のLRSの視野の重被領域で行う複数LRSの協調による移動 物体追跡法を述べる。移動物体検出に関しては文献[1]の方 法を用いる。 


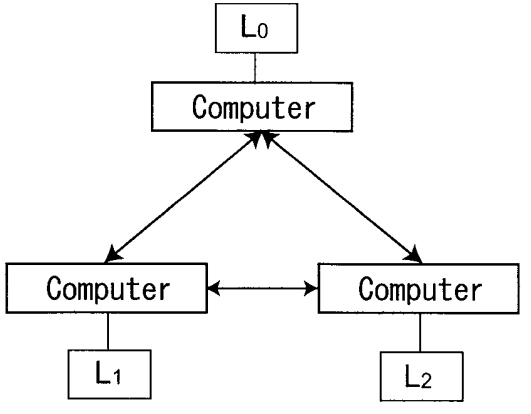

Fig.4 Network topology of LRS system

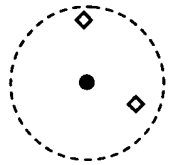

(a) Case 1

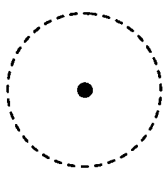

(d) Case 4

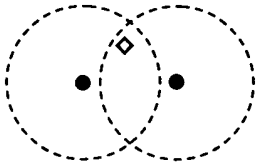

(b) Case 2

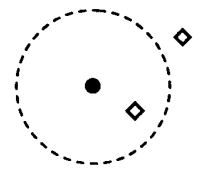

(c) Case 3

Fig.5 Tracking condition

\subsection{LRS 単独での移動物体追跡}

$L_{0}$ 単独による移動物体追跡を以トに述べる。なお， $L_{1}$ と $L_{2}$ による移動物体追跡は $L_{0}$ と同様である。

(1) カルマンフィルタによる移動物体追跡

ロボット代表点の初期位置を原点とした地上固定座標系 $\Sigma_{w}(O ; X Y)$ における移動物体の位置を $\left(x_{0}, y_{0}\right)$ と寸ると, 以下の状 態方程式が得られる。

$$
x_{0}(t)=\left(\begin{array}{cccc}
1 & \tau & 0 & 0 \\
0 & 1 & 0 & 0 \\
0 & 0 & 1 & \tau \\
0 & 0 & 0 & 1
\end{array}\right) x_{0}(t-1)+\left(\begin{array}{cc}
\tau^{2} / 2 & 0 \\
\tau & 0 \\
0 & \tau^{2} / 2 \\
0 & \tau
\end{array}\right) \Delta x_{0}(t-1)
$$

ただし， $x_{0}(t)=\left(x_{0}(t), \dot{x}_{0}(t), y_{0}(t), \dot{y}_{0}(t)\right)^{T}, \Delta x_{0}(t)=\left(\Delta \ddot{x}_{0}(t), \Delta \ddot{y}_{0}(t)\right)^{T}$ は微小な加速度外乱である。また。てはスキャン哇期である。

移動物体検出において $\Sigma_{w}$ における移動物体に関する観測值 $z_{0}(t)=\left(z_{x_{0}}(t), z_{y_{0}}(t)\right)^{T}$ が得られたとすると，以卜の観測方程式が成 文する。

$$
\begin{aligned}
& z_{0}(t)=\left(\begin{array}{cccc}
\cos \psi(t) & 0 & -\sin \psi(t) & 0 \\
\sin \psi(t) & 0 & \cos \psi(t) & 0
\end{array}\right) x_{0}(t) \\
& -\left(\begin{array}{cc}
\cos \psi(t) & -\sin \psi(t) \\
\sin \psi(t) & \cos \psi(t)
\end{array}\right) p(t)+\Delta z_{0}(t)
\end{aligned}
$$

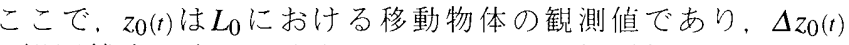
は観測雑音である。また， $p(t)$ と $\psi(t)$ はそれぞれ $L_{0}$ の位置と方位である。

式(7)(8)をもとにKFを構成し，追跡物体の位置・速度を推 定する。すなわち，各スキャンにおける追跡物体の予測位置 まわりに半径 $0.5[\mathrm{~m}]$ の有効領域 $(\mathrm{VG})$ を設け，そのVG内で得 られたひとつの観測值が追跡中の物体からのものとすると. 追跡物体の位置・速度が求まる。

$L_{0}$ は $L_{1}$ と $L_{2}$ の視野を認識している， $L_{0}$ が追跡する物体が $L_{1}\left(L_{2}\right)$ の視野内に存在する場合は，追跡物体の推定伯と推定 䛊差共分散 $I_{0}(t)=\left\{\hat{x}_{0}(t), P_{0}(t)\right\}$ を $L_{1}\left(L_{2}\right)$ に送信する。

(2) データアソシエーションと追跡管理

(1)ではVG内で得られる観測值はひとつであり，しかもそ の観測值は追跡物体と対応寸ると仮定した。しかし，その観 測值はいま注目している物体以外の物体かもしれないし，外 乱かもしれない。また，裬数の物体が移動する環境下では， 汶5(a)(b)に例を示すように、ひとつのVG内に複数の観測値 が得られたり、複数のVGの重複領域で観測值が得られる場 合もある。このような多様な状況トで物体を正確に追跡す るためには，複数の物体と褑数の観測值をうまく対応付ける ことが必要である。そこで，結合尤度関数を評価规範とした データアソシーエーション手法[1]を基礎に複数の移動物体 と観測值を対応付ける。

$L_{0}$ の視野内に新しい物体が出現したり，追跡物体が視野か ら出たり，他の物体による隠蔽など様々な状況が一般には発
生する。そのため, データアソシエーション手法によって対 応付けられなかった追跡物体や観測伯が存在する状況が発 生する。このような状況に対応するための追跡管理法を以 トに示す。

汹5(a)(c)に示すように，追跡物体と対応付けられない観測 値は新規物体と考え。KFにより追跡を開始する。ただし， 追跡開始後 15 スキャン以内に観測优が得られなくなった場 合は外乱として追跡を終了する。汹5(b)(d)のように観測值が 得られないことは，追跡物体が隠蔽された際に生じる。観測 值が得られなくなると KFの予測アルゴリズムのみで物体を 追跡し続け，30スキャン過ぎても観測值が得られない場合 は追跡を終厂する。

\section{2 複数 LRS の協調による移動物体追跡}

$L_{0}$ と $L_{1}$ を例に, 複数LRS の協調による移動物体追跡法を述 ベる.

(1) CI(Covariance Intersection)による移動物体追跡

同一の追跡物体が袯数のLRSの視野の重複領域に存在する 場合，各LRSが算出する追跡物体の情報をCI[6]を用いて融 合する。 $L_{0}$ と $L_{1}$ で追跡している物体の情報を $L_{0}$ で融合する 処理を以下に示す。

a) $L_{0}$ による追跡物体の予測值と予測誤差共分散を $I_{0}(t / t-1)=\left\{\hat{x}_{0}(t / t-1), P_{0}(t / t-1)\right\}, \quad L_{1}$ による追跡物体の推定 值と推定䛊差宾分散を $I_{1}(t)=\left\{\hat{x}_{1}(t), P_{1}(t)\right\}$ とする。 $I_{0}(t / t-1)$ と $I_{1}(t)$ を式 (9)に示すCIアルゴリズムにより融合し， $I_{0}^{+}(t)=\left\{\hat{x}_{0}^{+}(t), P_{0}^{+}(t)\right\}$ 在得る。

$$
\left\{\begin{array}{l}
P_{0}^{+-1}(t)=\omega_{1} P_{0}^{-1}(t / t-1)+\omega_{2} P_{1}^{-1}(t) \\
P_{0}^{+-1}(t) \hat{x}_{0}^{+}(t)=\omega_{1} P_{0}^{-1}(t / t-1) \hat{x}_{0}(t / t-1)+\omega_{2} P_{1}^{-1}(t) \hat{x}_{1}(t)
\end{array}\right.
$$

ただし， $\omega_{1}, \omega_{2}$ は $P_{0}^{+}(t)$ の行列式を最小とするもので， $\omega_{1}+\omega_{2}=1$ である.

b) a)で得た $I_{0}^{+}(t)$ と観測值 $z_{0}(t)$ よりカルマンフィルタの観測 吏新アルゴリズムをもとに，追跡物体の位置・速度の推 定值と推定梌差共分散 $I_{0}^{*}(t)=\left\{\hat{x}_{0}^{*}(t), P_{0}^{*}(t)\right\}$ を得る。

以上の処埋は，追跡物体が $L_{0} ， L_{1}$ の両方で観測できる場合 の処理であるが，追跡物体が観測できない場合は，以トのよ うに対応する。

- 追跡物体が $L_{0}$ で観測でき， $L_{1}$ で観測できない場合: $L_{0}$ は $I_{0}(t)$ を追跡物体の情報とする

- 追跡物体が $L_{0}$ で観測できず， $L_{1}$ で観測できる場合: $L_{0}$ は $L_{1}$ から送信された $I_{1}(t)$ を追跡物体の情報とする。

- 追跡物体が $L_{0}, L_{1}$ の雨方で観測できなかった場合: $L_{0}$ は $I_{0}(t / t-1)$ を追跡物体の情報とする。

(2) 袯数LRSの協調によるデータアソシエーションと追跡管理 


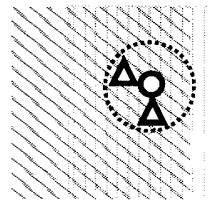

(a) Case 1

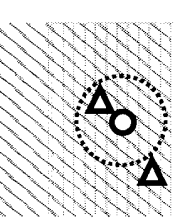

(d) Case 4

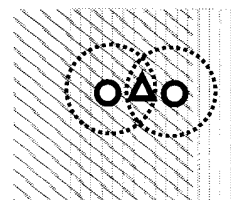

(b) Case 2

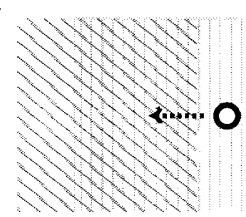

(e) Case 5

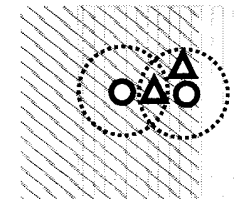

(c) Case 3

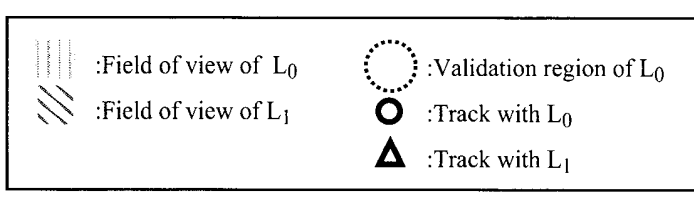

Fig.6 Condition of cooperative tracking

前項で述べた移動物体追跡を契現するためには，他のLRSか ら送られてきた追跡物体の情報が，現在追跡しているいずれ の追跡物体に対するものであるかを対応付ける必要がある。

物体追跡環境トでは，図6(a)〜(c)に示すように， $L_{0}$ におけ るひとつのVG内に $L_{1}$ の追跡物体が複数存在したり， $L_{0} に お ~$ ける複数のVG内に $L_{1}$ の追跡物体が存在する場合もある。ま た，図6(e)(f)に示すように，追跡物体が $L_{1}$ の視野から $L_{0}$ と $L_{1}$ の視野の重複領域 $(\mathrm{OA})$ へ移行したり， $L_{0}$ の視野から $\mathrm{OA}$ へ移 行する場合の対応も必要である。

このような状況に対応するため，以トに示すような被数 LRSの協調によるデータアソシエーションと追跡管埋を行う.

- OAに追跡物体が存在する場合(図6(a) (d)): $L_{0}$ における 追跡物体のVG内に $L_{1}$ の追跡物体が存在すれば。 $L_{0}$ はそ れらの物体を4.1(2)のデータアソシエーション手法によ り同一の物体として対応付ける。対応付けられない場 合， $L_{0} ， L_{1}$ では単独で物体追跡を継続する。

- 追跡物体が $L_{0}$ の視野から OAに移行する場合(図6(e)): $L_{0}$ における追跡物体のVG内に $L_{1}$ による観測值が入れば， $L_{1}$ はこの観測值を $L_{0}$ より送られてくる $I_{0}(t)$ に対するもの と対応付け， $I_{0}(t)$ を毛とに追跡を開始する。対応付けら れない場合は， $L_{0}$ は単独で物体追跡を継続し， $L_{1}$ は新規 物体として単独で追跡を開始する

- 追跡物体が $L_{1}$ の視野からOAに移行する場合(図6(f)): $L_{1}$ に おける追跡物体のVG内に $L_{0}$ による観測值が入れば， $L_{0}$ はこの観測值を $L_{1} よ り$ 送られてくる $I_{1}(t) に$ 対するものと 対応付け， $I_{1}(t)$ をもとに追跡を開始する。対応付けられ ない場合は， $L_{1}$ は単独で物体追跡を継続し， $L_{0}$ は新規物 体として単独で追跡を開始する。

\section{5. 移動物体追跡実験}

図7に示す室内環境で, $0.1 \sim 1.5[\mathrm{~m} / \mathrm{s}]$ の速度で歩行する 3 人の 歩行者を追跡する。ロボットは圀7の $(X, Y)=(0.0[\mathrm{~m}], 0.0[\mathrm{~m}])$ から, 最大 $0.3[\mathrm{~m} / \mathrm{s}]$ の速度で破線で示した経路を走行した。 また，歩行者は父差を繰り这しながらロボットの哇四を歩行 した。

汹8(a)に移動物体検出結果，(b)に追跡結果を示す。汹8(a) に示すように裬数の静止物体を移動物体と䛊認している. これは，ロボットと静止物体，步行者との位置関係により， 静止物体がLRSにより常時観測できないことから移動物体
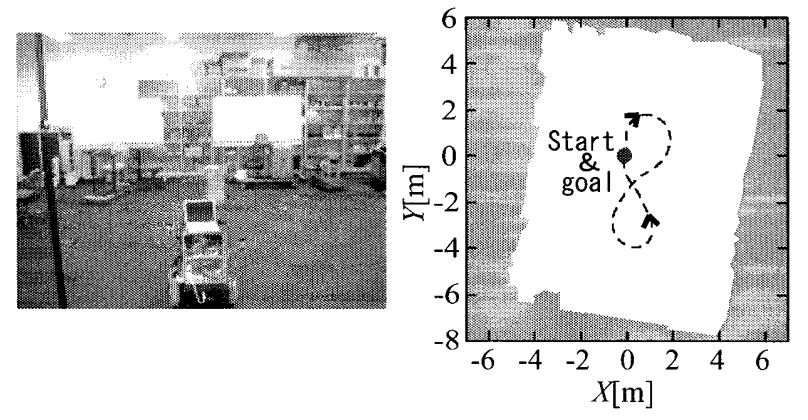

Fig.7 Experimental setup

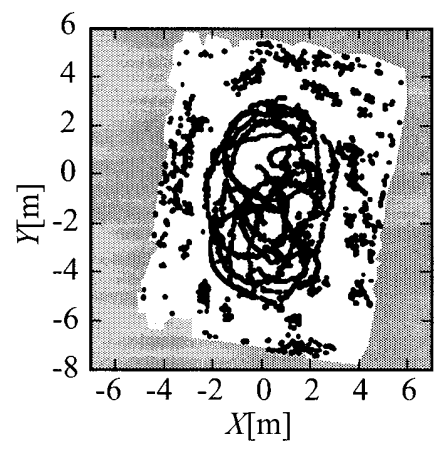

(a)Moving target detection

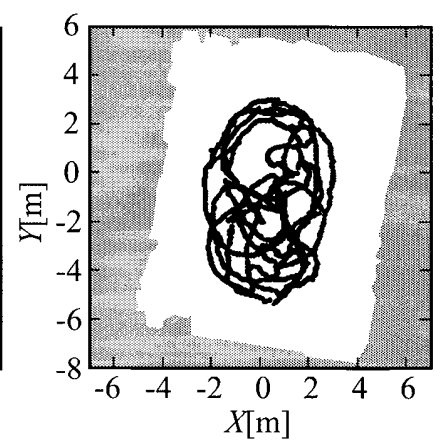

(b)Moving target tracking
Fig.8 Experimental result

と誤㗹する。しかし，静止物体からの観測值は出現と消失を 繰り这しており，追跡管理法によって外乱として処理され， 戍8(b)に示すように歩行者のみを追跡する。

\section{6. おわりに}

本諭文では、複数の車載LRSに関するキャリブレーション 法と移動物体を検出・追跡する方法を提案した。そして，室 内環境で複数の歩行者を追跡する垁験を行い，提案手法の有 効性をを示した。今後，LRSを搭載した複数のロボットが協調 して移動物体の検出・追跡を行うシステムに対して，提案手 法を適用する予定である。

\section{文献}

[1]橋本雅文, 緒方聡, 大場史憲, 阙四一郎, 本載レーザレンジセンサによ る裬数移秒物体の検出・追跡江, 日本機椷学会論文集, $\mathrm{C}$ 編, 72 巻, 717 岇, pp.162-170 (2006).

[2]松非介, 橋本雅文, 高橋和䖉, 被数レーザレンジセンサによる移動 物休検出・追跡法，第 49 回自動制御速合講演会諭文集，CD-ROM (2006).

[3] 劉焕軍，橋本雅文，又平知也，大場史憲，レーザレンジファインダに

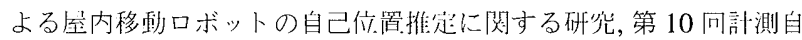
動制御学:会中国支部”产術講演会論文集，pp.62-63 (2001).

[4] Y.Bar-Shalom and T.E.Fortmann, Tracking and Data Association, Academic Press,Inc. (1988).

[5] 中村完行, 趙亦荽, 柴崎亮介, 坂本丰可, 大鉼朋生, 鈴川尚毅, 複数の レーザレンジスキャナを浦いた少行者トラッキングとその信賽性評

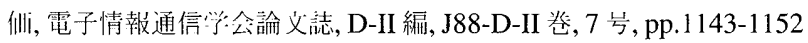
(2005).

[6] S. Julier and J.K.Uhlmann, General Decentralized Data Fusion with Covariance Intersection (CI), Handbook of Multisensor Data Fusion (D.L.Hall and J.Llinas, Eds.), CRC Press (2001). 